\title{
Estructura analógica: \\ soporte de creatividad lingüística \\ en greguerías para aprender verbos
}

Lucila Alvarez de la Cruz

Fecha de recepción: 29 de julio de 2019

Fecha de aceptación: 10 de septiembre de 2019

\section{Resumen}

$\mathrm{U}$ na de las competencias más importantes en bachillerato es el desarrollo de las habilidades de escritura; por eso, es indispensable promover estrategias de aprendizaje gramatical de forma situada que doten a los estudiantes de conocimientos explícitos sobre la lengua para comunicar sus ideas eficazmente. Para ello, el texto literario es un recurso valioso que fortalece la competencia lingüística a través de la creación poética. Aquí se ofrece una propuesta didáctica, cuyo soporte es la estructura analógica; en ella se combinan las funciones poética y metalingüística de la lengua, por medio de la producción de greguerías, para analizar cuál es la función del verbo. De esta manera, al reconocer el tipo de sintagma verbal escrito, se confirma si la intención comunicativa ha sido expresada correctamente.

Palabras clave: competencia lingüística, analogía, verbo, greguería, función poética, función metalingüística.

\section{Introducción}

Una de las competencias particulares de una clase de lengua es el empleo del lenguaje para comunicarse y como instrumento para aprender. Para que esto ocurra, el docente debe promover estrategias didácticas en las cuales los estudiantes reflexionen sobre el signo lingüístico que usan automáticamente en su vida diaria, hagan explícitas las reglas que aplican sin saber cómo y utilicen lo que saben con mayor efectividad (Uzcátegui, 2008). Bajo esta consigna se enmarca la necesidad de enseñar gramática con el fin de que los alumnos conozcan los elementos de su lengua para manipularla de acuerdo con sus intenciones comunicativas.

¿Es conveniente enseñar gramática en la escuela? Sí, cuando sus objetivos vayan más allá de aprender de memoria categorías gramaticales, reglas de concordancia, conjugación, listas de preposiciones y conjunciones (Uzcátegui, 2008). Estará justificado su aprendizaje cuando haya una relación evidente con la función comunicativa, conocimientos previos, intereses y necesidades de los estudiantes. El texto literario se ha catalogado como un emisor de alto valor comunicativo, debido a los códigos utilizados en la construcción del mensaje. La creatividad lingüística ayudará a los alumnos de primer grado de bachillerato a usar el lenguaje cotidiano con fines estéticos. Esto puede transformar su competencia lingüística por medio de la producción y análisis del sintagma verbal en frases poéticas de su autoría.

El programa de estudio de Taller de lectura y redacción en primer grado de bachillerato enfatiza una de las competencias disciplinares básicas: "Identifica, ordena e interpreta las ideas, datos y conceptos explícitos e implícitos en un texto, considerando el contexto en el que se generó y en el que se recibe" (Subsecretaría de Educación Media Superior, 2017: 11). Por lo anterior, el objetivo de este artículo es compartir una propuesta didáctica basada en la estructura analógica; en ella se potencia la creatividad lingüística a partir de la producción de greguerías, donde se manifiestan las funciones poética y metalingüística de la lengua, con el fin de comprender el papel gramatical del verbo.

\section{Desarrollo}

"Aprender a aprender" es una consigna que requiere "enseñar a pensar" a través de guías explícitas. La categorización 
es central para el pensamiento, y la estructura analógica es la respuesta para desarrollarla (Hofstadter \& Sander, 2013). La categorización es la manera en la que el estudiante organiza la información; su propósito es el aprendizaje significativo, porque a través de ella se obtienen mayores ventajas respecto a sólo memorizar datos de forma arbitraria.

Por su parte, la estructura analógica se caracteriza por el diseño de un enlace entre la información nueva relacionada con los conocimientos previos del alumno. Está compuesta por: a) el "tópico" o concepto "diana" que se va a aprender, generalmente abstracto y complejo (verbo); b) el "vehículo" con el cual se realiza la comparación (greguerías); c) los "conectivos lingüísticos" que establecen la relación del "tópico" con el "vehículo" (tipos); y $d$ ) la "explicación" (síntesis) que exhibe la correspondencia entre ellos (Díaz \& Hernández, 2010: 129).

La competencia lingüística se refiere a saber utilizar las reglas gramaticales en diversas situaciones comunicativas posibles (Chomsky, 1997). Jakobson (1984) describió seis funciones de la lengua, las cuales tienen que ver con la finalidad o propósito específico para iniciar un circuito de comunicación entre emisor y receptor a través de un código y canal en un contexto determinado. En esta propuesta didáctica se practican dos de ellas: la poética y la metalingüística.

Figura 1. Elementos de la propuesta involucrados en el desarrollo de la competencia lingüística

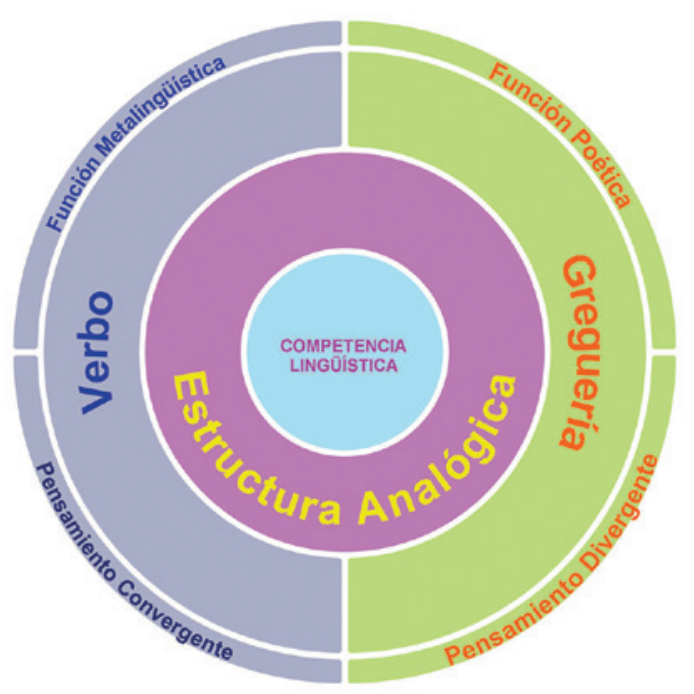

Fuente: elaborada por Lucila Alvarez de la Cruz.

La función poética o literaria describe la realidad en forma subjetiva y personal (Jakobson, 1984); usa el lenguaje figurado para otorgar fuerza expresiva a la pala- bra. Se observa en las siguientes frases inéditas: "el desprecio es la basura del corazón"; "la imaginación es la televisión de nuestra mente"; "los bolígrafos se desangran día a día"; "las neuronas son las empleadas del cerebro". Esta función se distingue porque manifiesta una construcción lingüística especial que intenta producir un efecto estético en el destinatario. La función metalingüística explica la lengua con sus propios recursos, es decir, es la reflexión expositiva sobre alguno de sus aspectos (Jakobson, 1984). Por ejemplo:

Un sintagma es una palabra o conjunto de palabras que se articula en torno a un núcleo y que puede ejercer una función sintáctica. El estrato sintáctico, considera las reglas de combinación de palabras como unidades significativas o lexemas, formadas por uno o más morfemas (Supisiche et al., 2016: 75).

Desde el punto de vista gramatical, el verbo funciona como núcleo del predicado; denota acción, estado o proceso; sus desinencias expresan modo, tiempo, número y persona (Real Academia Española, 2005). Se considera la palabra más importante, desde el punto de vista sintáctico. Se afirma, incluso, que sin él no hay oración (Supisiche et al., 2016). Los verbos se clasifican en: auxiliar, causativo, copulativo, defectivo, impersonal, intransitivo, irregular, personal, pronominal, regular y transitivo. Una de las diferencias entre los tipos de verbos radica en la necesidad de que los acompañen o no otros sintagmas para que su significado se entienda de manera completa. Hay verbos que sólo necesitan estar acompañados por quien realiza la acción; otros solicitan el agente y el elemento que completa su realización; hay algunos que requieren el agente, el tema, locación y objetivo; por último, hay otros que reúnen todo el significado en sí mismos.

La greguería es una creación del poeta español Ramón Gómez de la Serna; describe una característica con sentido metafórico y, en muchas ocasiones, presenta una relación analógica, como se observa en las siguientes producciones de su autoría: "El cocodrilo es una maleta que viaja por su cuenta"; "los plátanos envejecen en un solo día"; "la pulga hace guitarrista al perro"; "el colchón está lleno de ombligos" (Gómez, 2004: 69).

Las greguerías han sido clasificadas de acuerdo con la intención estética que persiguen. Se observan entre las categorías más representativas: imagen contenida en sintagma verbal, comparación o símil, morfemas verbales, estructuras sintácticas bimembres, consecutivas, condicionales, exclamativas, interrogativas, en forma de 
diálogo y anafóricas. Esta tipología se puede entrelazar con la clasificación de los verbos para crear relaciones pertinentes, con el objetivo de consolidar conocimientos gramaticales.

Tal propuesta didáctica se basa en la idea de que hay poca eficiencia para almacenar información aleatoria, pero hay éxito cuando se establecen relaciones (University of Aarthus, 2006). La clasificación del verbo y el análisis de greguerías permite construir un puente para conectar el aspecto conceptual entre ellos. La analogía es "una comparación intencionada que engendra una serie de proposiciones que indica que un objeto o evento (generalmente desconocido) es semejante a otro (generalmente conocido)" (Díaz \& Hernández, 2010: 129). Además, se manifiesta cuando dos o más conceptos son similares en algún aspecto de interés pedagógico, aunque en ellos pueda haber diferencias en otros sentidos.

La producción poética estimula nuestra creatividad lingüística. Gómez de la Serna pensaba que la greguería surgía espontáneamente de una cosa producida en la imaginación. Einstein afirmaba: "El conocimiento es limitado. La imaginación abarca el mundo" (Buzan, 2018: 45). En este caso, la aplicación del pensamiento lateral tiene su razón de ser en el uso óptimo de la información (De Bono, 2000). El pensamiento lateral tiene mucho en común con la creatividad, pero, mientras ésta constituye con frecuencia una descripción de resultados (concepto gramatical), aquél incluye la descripción de un proceso (greguería) (De Bono, 2000). En esta propuesta didáctica se recuperan también dos tipos de pensamiento: el "convergente", especializado en la solución de problemas basados en modelos conocidos, en cuyo ámbito se encuentra la respuesta lógica (concepto gramatical); y el "divergente", que inventa y repasa los conocimientos utilizando puntos de vista nuevos (creación de greguerías) (Serafini, 2019).

Para el desarrollo de la propuesta didáctica se recomiendan las siguientes actividades de forma general, debido a que la creatividad y recursos del profesor pueden enriquecerla con su estilo propio. Aquí es oportuno recuperar la competencia disciplinar básica implicada del programa de estudio de Taller de lectura y redacción: "Identifica, ordena e interpreta las ideas, datos y conceptos explícitos e implícitos en un texto considerando el contexto en el que se generó y en el que se recibe" (Subsecretaría de Educación Media Superior, 2017: 11). En esta ocasión, se desarrolla a través de las características de la estructura analógica, donde se busca que la promoción del uso de analogías se convierta en una estrategia de aprendizaje, debido a que el alumno será quien produzca el texto objeto de estudio y consolide el aparato teórico de forma inductiva. El docente evitará ser un transmisor de información para convertirse en facilitador de espacios de reflexión y asimilación por medio de la relación de conceptos clave.

La propuesta didáctica sugiere iniciar con una pregunta activadora y retomarla al final de la secuencia. Se recomiendan las siguientes: “¿por qué se parecen un verbo y una greguería?", “ ¿se podrían quitar los verbos a una greguería sin afectarla?”, “cómo la analogía une al verbo y a la greguería?", “¿por qué son vitales el verbo y la greguería?” o “ipor qué muere la greguería sin el verbo?”. La idea es provocar curiosidad para descubrir la respuesta durante el proceso de aprendizaje. Con el objetivo de asegurar que los alumnos distingan la estructura analógica, se aconseja diseñar una presentación digital de imágenes de inventos, inspirados en cualidades del reino animal, para proyectarse en el salón. Se recomienda conseguir el video "GregueríasRamón Gómez de la Serna” (Montero, 2014) de una plataforma en internet; en él se ofrecen ejemplos llamativos con recursos sonoros, lúdicos y atractivos. Al finalizar estas actividades se pueden incluir preguntas como: “¿cuál es la intención de mostrar los inventos?”, “¿conoces otro invento inspirado en la naturaleza?", "¿qué tipo de frases se compartieron en el video?”, “qué es una analogía?” y “¿cómo se define greguería?”.

En un segundo momento se recomienda trabajar colaborativamente. En esta sesión se requiere tomar como base de inspiración imágenes de revistas, hojas de colores, plumones y pegamento para diseñar un catálogo de frases poéticas ilustradas. Aquí se formalizarán los conceptos gramaticales basados en la categorización, al crear greguerías y luego analizarlas, lo cual permitirá comprender qué es un verbo, sus tipos y funciones en textos escritos de forma intencionada. El andamiaje puede llevar varias sesiones de trabajo de acuerdo al desempeño de los alumnos.

Una vez que se ha asimilado el aprendizaje de los conceptos clave, el último momento propone la incursión musical en el salón. Los alumnos reciben hojas con las letras de algunas canciones, a las cuales se les han quitado los verbos, para que las completen una vez que las escuchan. Ésta es otra oportunidad para reconocer la función de los verbos en una intención comunicativa situada y con lenguaje figurado.

Con el propósito de evaluar el desempeño de aprendizaje, se sugiere utilizar fichas de observación, cuestionarios de diagnóstico, de proceso y metacognitivos (tanto de conocimientos gramaticales como de regulación de la actividad). Las preguntas de metacognición al cierre de la secuencia pueden ser: “¿qué me pareció la actividad?", “¿qué relación encuentro entre la clasificación del verbo 
y la greguería?”, “¿tengo más clara la función de los verbos?", “¿qué utilidad tuvo la analogía en este proceso de aprendizaje?". Para terminar, se retoma la pregunta generadora, o bien, se puede usar un ejemplo así: “¿Qué tiene que ver la frase de Mark Twain: 'Todos somos una luna y tenemos un lado oscuro que no mostramos a nadie' con la analogía/verbo/greguería?". Será interesante leer cómo se justifica la frase con cada uno de los conceptos clave.

\section{Conclusión}

Las escuelas del futuro se planificarán para pensar (Bruer, 1995). Las cualidades de esta propuesta didáctica, que pueden validar su estrategia significativa ligada a la práctica de producir y pensar, están asociadas con las características de la enseñanza creativa: "naturaleza flexible, métodos de enseñanza indirecta, imaginativa, relación interpersonal, autodirección, valoración y realización" (Pacheco, 2003: 24).

Esta propuesta tiene una "naturaleza flexible", pues se adapta a las necesidades de los alumnos, a quienes se les proporcionan conocimientos explícitos para el desarrollo de la competencia lingüística de su propia lengua. Ofrece, igualmente, "métodos de enseñanza indirecta", los cuales estimulan la capacidad relacional (analogía), pone en movimiento las operaciones connotativas (función metalingüística y poética) y fomenta el pensamiento creativo (producción poética). Es, también, "imaginativa", ya que diseña frases poéticas con sentido lúdico. Del mismo modo, favorece la "relación interpersonal", donde el trabajo colaborativo produce una complicidad creadora. Lleva "autodirección": el maestro propone estrategias de aprendizaje y los alumnos dirigen y producen el significado de los conceptos claves. Así también, implica "autovaloración y autorrealización", debido a que los estudiantes se convierten en personas autónomas e independientes, al fortalecer sus competencias lingüísticas a través del dominio gramatical.

Aprender sobre aspectos del verbo relacionados con la estructura analógica por medio de la producción de greguerías, puede garantizar un aprendizaje significativo debido a su naturaleza creativa. La generación de una diversidad de estímulos y estrategias para categorizar la información nueva será determinante en el proceso de aprendizaje. En este caso, conocer aspectos gramaticales resulta ser de las actividades menos atractivas para los alumnos, pero necesaria en la consolidación de su competencia lingüística.

\section{Fuentes de consulta}

Bruer, J. (1995). Escuelas para pensar. Una ciencia del aprendizaje en el aula. España: Paidós.

Buzan. T. (2018). Mapas mentales. Aprende a usar la herramienta de pensamiento más poderosa del universo. México: Planeta.

Chomsky, N. (1997). Aspectos de la teoría de la sintaxis. España: Gedisa.

De Bono, E. (2000). El pensamiento lateral. Manual de creatividad. Argentina: Paidós.

Díaz Barriga, F. \& Hernández Rojas, G. (2010). Estrategias docentes para un aprendizaje significativo. Una interpretación constructivista. México: McGraw Hill.

Gómez de la Serna, R. (2004). Greguerías. España: Cátedra.

Hofstadter, D. \& Sander, E. (2013). Surfaces and Essences. Analogy as the Fuel and Fire of Thinking. New York: Basic Books.

Jakobson, R. (1984). Ensayos de lingüística general. España: Ariel.

Montero, B. [cuentacuentos Beatriz Montero]. (14/abril/ 2014). Greguerías - Ramón Gómez de la Serna [Video]. YouTube. Recuperado de https://bit.ly/2Nfi74v.

Pacheco, V. (2003). La inteligencia y el pensamiento creativo: aportes históricos en la educación. Educación, 27, 17-26. Recuperado de https://bit.ly/2oK78ao.

Real Academia Española. (2005). Diccionario panhispánico de dudas. Colombia: Santillana.

Serafini, M. (2019). Cómo redactar un tema. Piensa, planifica y escribe. México: Paidós.

Subsecretaría de Educación Media Superior. (2017). Programa de estudios. Taller de lectura y redacción I. Primer semestre. Dirección General de Bachillerato. Recuperado de https://bit.ly/2VV27b9.

Supisiche, P. et al. (2016). Enseñar gramática. Propuesta para docentes. Argentina: Editorial Brujas.

University of Aarthus (Prod.), Brabrand C. \& Andersen J. (Dir.) (2006). Teaching Teaching \& Understanding Understanding. 19 minute award-winning short-film (DVD) about Constructive Alignment. Dinamarca.

Uzcátegui, Q. (2008). Gramática y enseñanza de la lengua. Conferencia en el marco del Encuentro Nacional de Docentes e Investigadores de Lingüística (ENDIL). Revista de Artes y Humanidades UNICA, 9, 243-250. Recuperado de: https://bit.ly/31ne8qM. 